\title{
Cicadas (Hemiptera, Auchenorrhyncha, Cicadidae) from Brasília (Brazil): exuviae of the last instar with key of the species
}

\author{
Paulo César Motta ${ }^{1}$ \\ ${ }_{1}$ Departamento de Zoologia, Universidade de Brasília.70910-900 Brasília, Distrito Federal, Brasil. E-mail: mottapc@unb.br
}

\begin{abstract}
Eight cicada species were collected in an urban area of Brasília (Brazil). Their nymphal casts were characterized and a dichotomous key was prepared to identify cicada species.
\end{abstract}

KEY WORDS. Cerrado, Dorisiana, Fidicina, Fidicinoides, Majeorona, Quesada, Neotropical.

\begin{abstract}
The annual appearance of cicadas (Hemiptera, Auchenorrhyncha, Cicadidae) with their exuviae shed on tree trunks and their characteristic acoustic signals, occurring from the middle of August until December, is so intense in Brasilia that it even becomes an obligatory subject in the local media. Despite their abundance and eloquence, there are no studies about them. The use of morphological exuviae characterization to identify species is important because it is useful for population and community studies, insect plant interactions as well as phylogenetic and taxonomic purposes. MarTinelli \& ZuCHI (1997) utilized adult cicada characters from the state of São Paulo. The objective of this study is to record the cicadas which occur in an urban area of Brasília, as well as to characterize the general morphology of the exuviae and construct a dichotomous key for species identification based on cicada exuviae.
\end{abstract}

\section{MATERIAL AND METHODS}

The city of Brasília $\left(15^{\circ} 46^{\prime} \mathrm{S}, 47^{\circ} 55^{\prime} \mathrm{W}\right.$, altitude around $1000 \mathrm{~m}$ ) is located in the cerrado region, at the Brazilian Central Plateau. The climate, following the classification system of Köppen, is Aw, being characterized more by precipitation than temperature, with a dry season extending from the middle of May until mid-September, and a rainy season during the rest of the year.

Emerging individuals were collected from September to December, 1999, in an urban area of Brasília. Ivone R. Diniz (University of Brasília, Distrito Federal, Brazil) collected the specimens, Nilza M. Martinelli (São Paulo State University, Jaboticabal, São Paulo State, Brazil) and Allen F. Sanborn (Barry University, Florida, USA) identified the species. Collected specimens are deposited in the Entomological Museum of the University of Brasília. Nymphal skins can be classified to sex by the developing genitalia at the tip of the abdomen. Several exuviae from each sex, for each species, were examined and the body length between the rostrum and last abdominal segment was measured with digital calipers $(0,01 \mathrm{~mm}$ resolution).

\section{RESULTS AND DISCUSSION}

\section{Exuviae description}

Until now eight species were collected in the urban area of Brasília: Quesada gigas (Olivier, 1790), Fidicina mannifera (Fabricius, 1803), Fidicinoides pronoe (Walker, 1850), Dorisiana viridis (Olivier, 1790), Dorisiana drewseni (Stål, 1854), Majeorona aper (Walker, 1850), Fidicinoides determinata (Walker, 1858) and Dorisiana sp. The nymphal skins of cicadas can be used as a reliable indicator and the body length and general coloration of the exuviae are good cues for species determination. The male developing genitalia (sternum 10) are very characteristic for each species (Figs. 1, 4-10). But many morphological characters present in the antennae, legs and female developing genitalia (Fig. 2) are very similar among the eight species. Besides the external developing genitalia there is a dimorphism in size of the exuviae between the sexes for some species (Tab. I). The males are bigger than females in Q. gigas, F. determinata and $D$. viridis. In Dorisiana sp. the opposite occurs.

An example of general exuviae characterization, following the description of Quesada gigas. Light beige coloration, with small white patches, specially on the lateral surfaces; they are the largest exuviae of Brasília (see Tab. I), with males ( 3.7 to $4.4 \mathrm{~cm}$ ) being larger than females (3.4 to 4.0 $\mathrm{cm})$. First sternite bearing a median protuberance. Antennae with nine segments. Anterior femur (Fig. 3) is the most developed segment, adapted for digging, dark brown, teeth and spines black, bearing a three subset of spines (or tooth) separated by a short distance from each other. First tooth (in proximal to distal direction) is the largest (Fig. $3 \mathrm{t} 1$ ), most robust with a small bifurcation; intermediary subset composed by a double spine (Fig. 3 t2), with the most distal being half of the size in relation to their partner. Last subset in a series of seven to eight small teeth (exceptionally five or six), known as the comb, up to apical portion, spine larger than the others. $Q$. gigas from São Paulo state presents different exuviae morphology in relation to body length, antennae and anterior femur (MARTINELli \& ZuCHI 1987). 


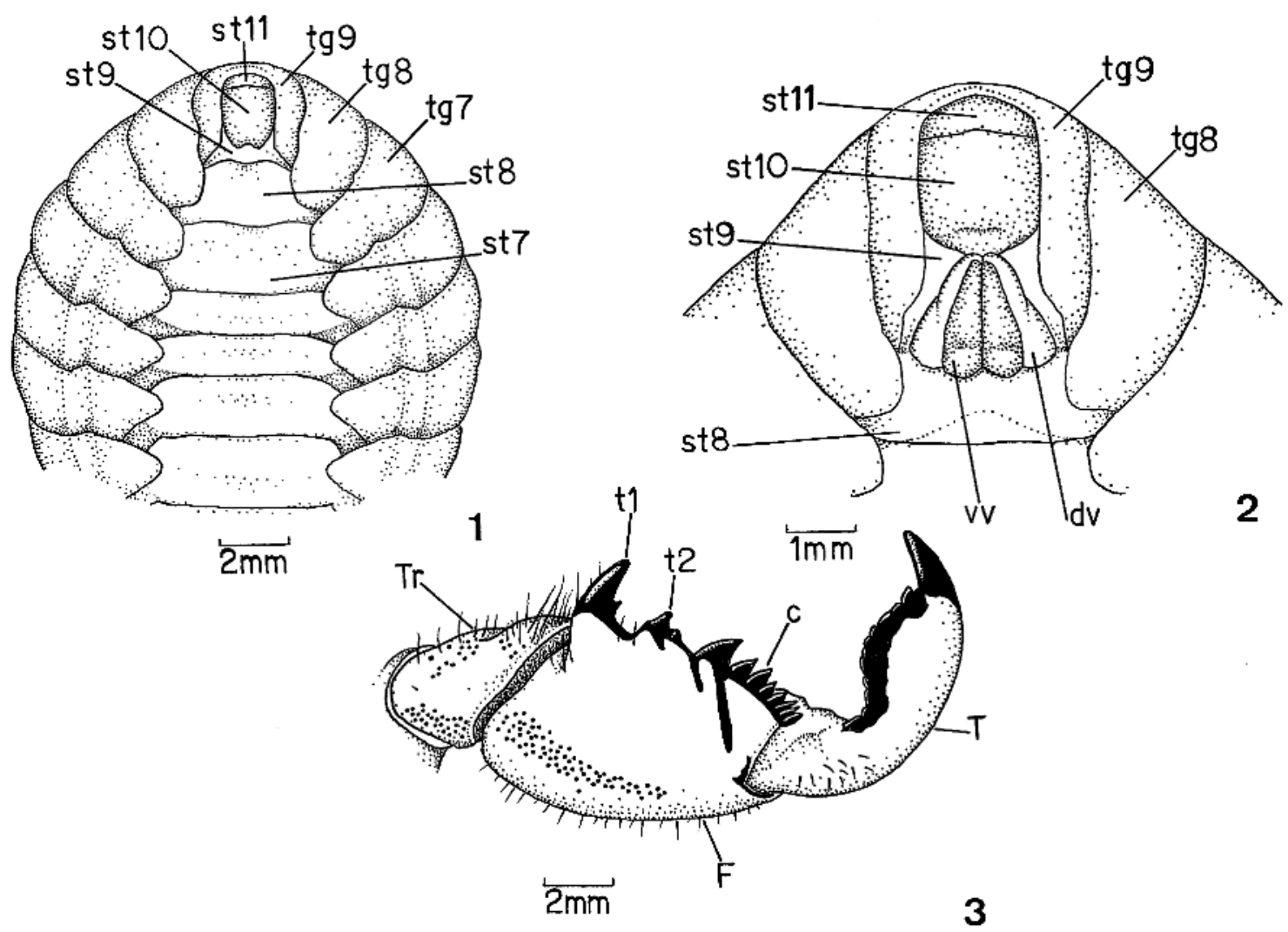

Figs. 1-3. (1) Ventral view of male abdomen (Majeorona aper); (2) ventral overview of female developing genitalia (Fidicina mannifera); (3) First leg (trochanter, femur and tibia) of Quesada gigas. (c) Femoral comb, (dv) dorsal valve or gonapophysis, (F) femur, (st) sternum, ( $\mathrm{T}$ ) tibia, (tg) tergum, (Tr) trochanter, $(\mathrm{t} 1, \mathrm{t} 2)$ femoral teeth, (vv) ventral valve or gonapophysis. The terms are from BoulaRD (1965) and Chapman (1998).

Table I. General coloration and body length of male and female cicada exuviae from Brasília. White patches present $(\mathrm{Y})$ or absent $(\mathrm{N})$. (N) Examined number, (Min and Max) minimum and maximum length observed, (M) mean, ( $\mathrm{S}$ and NS) significative and no significative difference, (SD) standard deviation, $(\mathrm{t}) \mathrm{t}$ test. All measures in centimeters.

\begin{tabular}{|c|c|c|c|c|c|c|c|c|c|c|c|c|c|c|}
\hline & \multirow{2}{*}{ Color } & \multirow{2}{*}{ Patches - } & \multicolumn{5}{|c|}{ Male } & \multicolumn{5}{|c|}{ Female } & \multicolumn{2}{|c|}{ Significance } \\
\hline & & & $\mathrm{N}$ & Min & Max & M & SD & $\mathrm{N}$ & Min & Max & M & SD & $\mathrm{t}$ & $\mathrm{p}$ \\
\hline Quesada gigas & Light beige & $\mathrm{Y}$ & 20 & 3.72 & 4.37 & 4.02 & 0.14 & 20 & 3.41 & 4.04 & 3.77 & 0.15 & -5.416 & $0.000 \mathrm{~S}$ \\
\hline Fidicinoides determinata & Beige & $\mathrm{Y} / \mathrm{N}$ & 20 & 3.17 & 3.76 & 3.46 & 0.59 & 20 & 3.00 & 3.60 & 3.28 & 0.16 & -3.579 & $0.001 \mathrm{~S}$ \\
\hline Majeorona aper & Dark beige & $\mathrm{N}$ & 20 & 3.10 & 3.72 & 3.41 & 2.02 & 20 & 2.93 & 3.53 & 3.30 & 0.17 & -1.744 & 0.089 NS \\
\hline Fidicina mannifera & Dark beige & $\mathrm{N}$ & 20 & 2.75 & 3.27 & 3.04 & 0.16 & 20 & 2.50 & 3.26 & 2.96 & 0.19 & -1.542 & $0.132 \mathrm{NS}$ \\
\hline Fidicinoides pronoe & Light beige & $\mathrm{Y} / \mathrm{N}$ & 20 & 2.32 & 2.84 & 2.54 & 0.14 & 15 & 2.24 & 2.72 & 2.50 & 0.14 & -0.955 & $0.347 \mathrm{NS}$ \\
\hline Dorisiana sp. & Whitish beige & $\mathrm{N}$ & 20 & 1.85 & 2.21 & 2.06 & 0.10 & 20 & 1.98 & 2.42 & 2.19 & 0.12 & 3.517 & $0.001 \mathrm{~S}$ \\
\hline Dorisiana viridis & Light beige & $\mathrm{N}$ & 20 & 1.76 & 2.06 & 1.94 & 0.09 & 20 & 1.67 & 1.99 & 1.78 & 0.10 & -5.362 & $0.000 \mathrm{~S}$ \\
\hline Dorisiana drewseni & Light beige & $\mathrm{N}$ & 20 & 1.35 & 1.64 & 1.47 & 0.08 & 20 & 1.32 & 1.69 & 1.49 & 0.10 & 0.421 & $0.676 \mathrm{NS}$ \\
\hline
\end{tabular}

Revista Brasileira de Zoologia 20 (1): 19-22, março 2003 

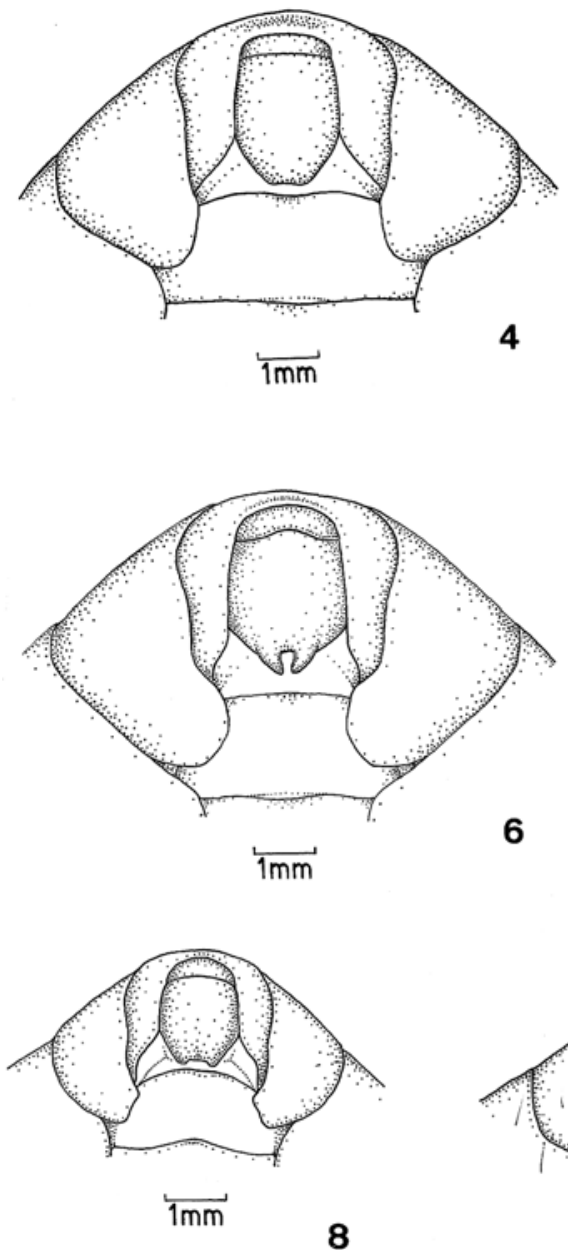

8

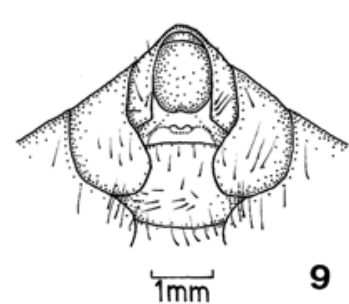

9
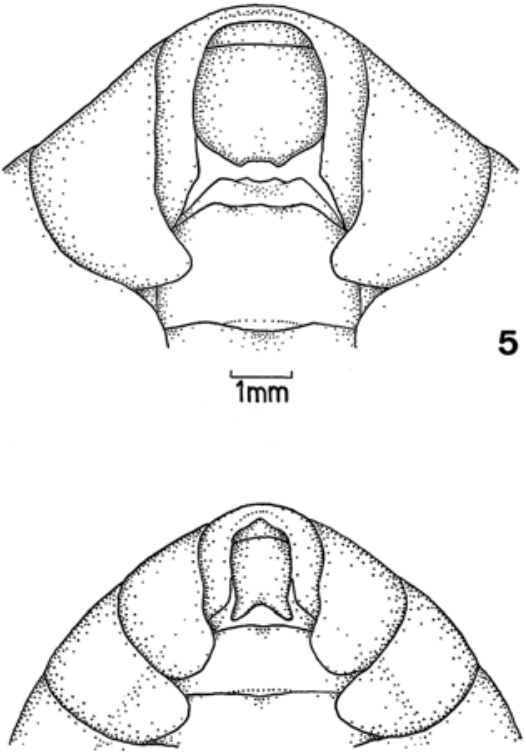

$\stackrel{\mathrm{mm}}{\mathrm{m}}$ 7

Figs. 4-10. Terminal segments of the male nymphal exuviae (ventral view). (4) Fidicinoides determinata; (5) Quesada gigas; (6) Fidicina mannifera; (7) Dorisiana viridis; (8) Fidicinoides pronoe; (9) Dorisiana sp.; (10) Dorisiana drewseni.

Some aspects of general appearance probably are due to conditions of eclosion. Rostrum stylet in horizontal position near to base of hind coxae or standing (vertical) close to anterior femur. Waist between the thorax and abdomen more or less accentuated according to exuviae curvature. In the same way, total length of exuviae depends on the grade of the arch. In addition, the straighter the exuviae is, the longer it will become. The samples of this study apparently include this length diversity but, as expected, there are individuals which deviate from the normal length range. For example, some $Q$. gigas male exuviae can be $3.2 \mathrm{~cm}$ although the minimum expected was about $3.5 \mathrm{~cm}$.

\section{Key for species identification using exuviae}

Species may be differentiated by the morphology of their exuviae (see Figs. 1, 4-10). Females of M. aper and F. mannifera present dubious characteristics and are not easy to distinguish them.
1. Large or medium size, length $\geq 2.6 \mathrm{~cm}$.......................... 2

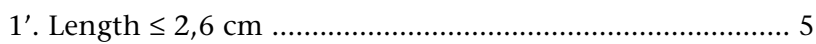

2. Light beige coloration ....................................................... 3

2'. Dark beige/brown coloration .......................................... 4

3. Light beige with white patches, male $>3.7 \mathrm{~cm}$, female $>3.3$ $\mathrm{cm}$ Quesada gigas

3'. Normal beige with or without white patches; medium size, male: 3.1-3.8 cm, female: 3.0-3.4 cm; male developing genitalia longer than wider and without anterior barbs; profemoral intermediary tooth single or slightly undulated Fidicinoides determinata

4. Medium large (male: $3-3.7 \mathrm{~cm}$; female: $2.9-3.5 \mathrm{~cm}$ ), light gray sternites, generally with soil attached, male developing genitalia with two light protuberances ..... Majeorona aper

4'. Medium small (male: $2.7-3.3 \mathrm{~cm}$; female: $2.5-3.3 \mathrm{~cm}$ ), more intense coloration, more "glossy", dark gray sternites; male

Revista Brasileira de Zoologia 20 (1): 19-22, março 2003 
developing genitalia with two proximate barbs; profemur darker coloration Fidicina mannifera

5. Length: 2.2-2.6 cm, light beige, white patches can be present, normal setae Fidicinoides pronoe

$5^{\prime}$. Not as above.

6. Length: 1.8-2.4 cm, whitish beige coloration, pilous body larger and more abundant setae Dorisiana sp.

6'. Normal light beige coloration, normal setae

7. Small (male: 1.6-2.1 cm), male developing genitalia with two barbs Dorisiana viridis

7'. Very small (male $<=1.6 \mathrm{~cm}$ ), male developing genitalia with two protuberances. Dorisiana drewseni

\section{ACKNOWLEDGMENTS}

Kiniti Kitayama and Ivone R. Diniz first stimulated my interest of cicadas. Carlos E. G. Pinheiro and his students used the dichotomous key and made helpful comments. Núbia S. L. de Souza drew the figures. I would also like to thank Nelsônia R. de Morais, Válber M. Batista and Camila D. R. Ribeiro for their assistance in this research. J. Grazia, G. S. Carvalho and one anonymous referee made critical evaluation. A.M. Sakakibara reviewed the manuscript and suggested pertinent improvements.

\section{REFERENCES}

Boulard, M. 1965. Notes sur la biologie larvaire des cigales (Hom. Cicadidae). Annales de la Societe Entomologique de France, Paris, 1 (3): 503-521.

ChApMAn, R.F. 1998. The insects, structure and function. Cambridge, Cambridge University Press, $4^{\text {th }}$ ed, 770p.

Martinelli, N.M. \& R.A. ZuCChI. 1987. Cigarras associadas ao cafeeiro. I. Gênero Quesada Distant, 1905 (Homoptera, Cicadidae, Cicadinae). Anais da Sociedade Entomológica do Brasil, Londrina, 16: 51-60.

Martinelli, N.M. \& R.A. Zucchi. 1997. Cigarras (Hemiptera: Cicadidae: Tibicinae) associadas ao cafeeiro: distribuição, hospedeiros e chave para as espécies. Anais da Socidedade Entomológica do Brasil, Londrina, 26:133-143.

Received in 01.VIII.2002; accepted in 19.II.2003. 